\title{
¿MORAL DEL DEBER O MORAL DE LA VIRTUD? *
}

OSVALDO N. GUARIGLIA

Centro de Investigaciones

Filosóficas, CONICET y

Universidad de La Plata,

Argentina

El presente trabajo se ocupa de un aspecto de la moral que, a pesar de plantearse en el plano personal, tiene consecuencias directas e inmediatas en el plano de la moral pública o ciudadana. El que constituya un tema central tanto para la moral como para la filosofía política no es, por cierto, casual. El campo de la moral está formado por las relaciones de los hombres entre sí dentro del marco de la vida comunitaria, social y política, de modo tal que la reflexión ética habrá inevitablemente de exhibir este entretejido indivisible de lo moral y lo político en el plano teórico.

La cuestión que se formula este trabajo es la siguiente: ¿cómo es posible que actuemos moralmente?, y examina las dos respuestas que, a juicio del autor, continúan siendo las más importantes aún dentro del pensamiento filosófico contemporáneo. Son éstas las que he denominado, al modo tradicional, moral del deber y moral de la virtud.

Por cierto, no es mi intención desarrollar en el breve espacio de que dispongo cada una de estas dos respuestas en detalle, sino más bien examinar en ambos casos aquellas características que yo considero fundamentales en las mismas. El tono del examen es crítico y su conclusión, en cierto modo, aporética. Pues tanto la una como la otra fallan en algún aspecto importante, dejando abierta la puerta para formas a veces graves de escepticismo moral.

* Este trabajo fue leido en la mesa redonda organizada por el Instituto de Investigaciones Filosóficas de la UNAM y coordinada por el Prof. Dr. Fernando Salmerón sobre "Moral Pública y Moral Privada" en el XI Congreso Interamericano de Filosofía, Guadala jara, noviembre de 1985. Agradezco al Prof. Salmerón la invitación a participar en dicho evento. 
Como filósofos debemos enfrentarnos con una evidencia, a veces más oculta por las tranquilas aguas de la vida política y social, otras, en cambio, brutal y directamente puesta al descubierto por ciertas crisis particularmente graves en la historia de las sociedades, evidencia que en última instancia es el aguijón punzante y permanente de la reflexión moral: la existencia de grupos sociales que actúan tanto privada como públicamente de una manera completa y extremadamente inmoral. No me estoy refiriendo a los habituales casos marginales que se dan en toda sociedad, sino a aquellos grupos organizados que constituyen una parte importante de ella, los cuales tanto en la lucha por la posesión del poder como en el ejercicio del mismo, cuando circunstancialmente lo obtienen, cometen toda suerte de crímenes, vejámenes y asesinatos. La existencia de movimientos terroristas de los más variados signos y orientaciones políticas, pero en especial aquéllos armados y comandados desde el Estado es la demostración más palpable de la inexistencia de una ética normativa válida efectivamente para todos, que medie entre las conductas privadas y las acciones públicas y contribuya a la regulación equitativa y pacífica de los conflictos. Desde luego, la visión de la tarea de la reflexión ética que aquí sostengo supone que la misma tiene por naturaleza un fuerte compromiso con la acción social y política de los miembros de la sociedad en la que se engendra y procura, a su vez, incidir mediante el ejercicio del instrumental conceptual propio del filósofo en la evolución futura de ésta.

La pregunta que formulo recoge, a mi entender, esta preocupación directa por la acción moral, pues lo que se pretende investigar es justamente el problema de la traducción de proposiciones normativas teóricamente bien fundadas en máximas de conducta efectivamente vigentes para todos o la mayoría de los agentes morales. Solamente habiendo logrado un cierto grado de claridad sobre este problema, po- 
dremos, luego, circunscribir el fenómeno social del agente inmoral.

1. Por cierto, cualquier intento de clasificación de las distintas teorías morales es inevitablemente deficiente. A pesar de ello, resulta indispensable proponer una caracterización de aquellos postulados mínimos que identifican determinados tipos de moral por contraposición a otros. No creo que haya discrepancias sobre el paradigma de moral que voy a escoger del deber: me refiero a la ética kantiana, la cual ha ejercido y ejerce aún un influjo tan profundo como merecido en casi todas las propuestas actuales de fundamentación de la ética. Este influjo se manifiesta preponderantemente en la estructura lógica de la fundamentación y en la consecuente concepción general de la conexión entre sistema normativo y acción.

Ahora bien: existen en Kant mismo dos modelos distintos de una moral del deber, uno que voy a denominar sistemático, y otro que voy a denominar crítico. El primero corresponde al desarrollado por Kant en su vejez y expuesto en los Fundamentos metafísicos de la teoría de la virtud (1797): esquemáticamente consiste en postular principios puros, a priori, de la ética, que determinan fines cuya realización constituye al mismo tiempo un deber para todo hombre, tal que este deber fuerza a actuar en contra de las inclinaciones a fin de alcanzar aquellos fines $a$ priori por medio de su acción. ${ }^{* *}$ Las acciones particulares, por lo tanto, deben ser deducidas de estos principios últimos, de modo tal que el efecto de la voluntad consiste en cada caso en hacer coincidir el acto individual con el acto ideal deducido de la norma. Es por ello que, de acuerdo con Kant, la doctrina ética elemental (Ethische Elementarlehre) se divide en 'dogmática' y 'casuística', cada una de las cuales

1 MS-TL, IV, pp. 514-515.

** Las abreviaturas utilizadas están aclaradas en las referencias, al final del artículo. 
tiene que ver justamente con la deducción a partir de principios generales, por un lado, y su aplicación al caso particular, por el otro. ${ }^{2}$

El segundo modelo de ética del deber, el crítico, es el que Kant mismo presentó por primera vez en la Fundamentación de la metafísica de las costumbres. En ésta la noción del Deber (Pflicht) es considerada como una evidencia inmediata de la conciencia moral, que todo hombre posee espontáneamente con una certidumbre completa, evidencia que constituye el punto a partir del cual el filósofo inicia su reflexión en busca de los fundamentos lógicamente constringentes de la misma. En esta versión de la ética kantiana, la ley moral no es ni lo que engendra el conocimiento moral ni lo que constituye el hecho moral mismo. Ambos son preexistentes e insustituibles. Lo que la ley moral aporta mediante la universalización de la máxima es solamente un criterio lógicamente infalible para distinguir las obligaciones absolutas o apodícticas de aquellas otras que sólo emergen bajo las condiciones de un fin distinto que se quiere alcanzar. Según esta concepción, la conciencia moral tiene una existencia inmediata en el hombre común y es la fuente de una certidumbre indubitable en sus decisiones morales: "Pero si se pregunta: ¿qué es propiamente la moralidad pura, con la que, como piedra de toque, se tiene que poner a prueba el contenido moral de cada acción?, tengo que confesar que solamente los filósofos pueden hacer dudar sobre la decisión con respecto a esta cuestión. Pues en la razón común de los hombres está decidida hace tiempo, y la verdad no por fórmulas universales abstractas, sino por el uso corriente $\mathrm{y}$, por así decirlo, de un modo similar a la diferencia entre la mano derecha y la izquierda".

Existen importantes diferencias entre la moral sistemática y la moral crítica del deber, en especial con relación a lo

$2 M S-F L$, IV, pp. 543-546.

3 $K p V$, IV, p. 292. 
que podemos denominar la representación de la ley moral. En el primer caso, esta representación es postulada como un principio universal a la manera de un axioma, del cual se desprende como una matemática normativa todo el cuerpo de prescripciones para los actos particulares que deben dominar la acción. En el segundo caso, en cambio, la noción misma de ley está incorporada en la conciencia inmediata del Deber en cada caso particular, es decir, en la conciencia moral del agente frente a la acción singular, aun cuando esa conciencia no tenga un carácter discursivo sino que se manifiesta, como sostiene L. Nelson, únicamente en el sentimiento del Deber. En el caso de la moral sistemática, por lo tanto, es el mismo principio el que tiene en sí una fuerza directamente moral e imperativa, que se transmite inferencialmente a los mandatos, los cuales tienen siempre un carácter coercitivo y universal. En el caso de la ética crítica, no es el principio mismo el que confiere imperatividad al mandato que constituye el deber, sino que éste se da por supuesto como un motivo inmediato que fuerza a actuar contra toda posible inclinación natural contraria y es, por así decir, independiente de la ley moral. Quienes sostienen este tipo de moral del deber, como L. Nelson o R. Hare, confieren al principio de universalidad un carácter exclusivamente lógico y no moral. En el caso de Nelson, este principio constituye el contenido de la ley moral, una proposición universalmente válida que determina en cada caso en qué consiste el deber, pero no este mismo deber. En efecto, el deber, esto es, actuar moralmente, consiste tanto para Kant como para Nelson ${ }^{4}$ en actuar por respeto a la ley, independientemente de cuál sea esta ley. Si bien en Hare la cuestión no aparece tan claramente separada, es evidente que todo su argumento en favor de una separación estricta entre el principio lógico de la universalidad, por un lado, y una norma moral substancial que prescribiera algo así como un comportamiento

4 $K p V$, \$ 74, pp. 106 ss. 
adecuado a ese principio, ${ }^{5}$ por el otro, está dirigido a distinguir el carácter teórico de la universalidad del carácter moral de la prescriptividad, que cada uno debe asumir independientemente y, por así decirlo, mediante una decisión subjetiva.

Si ahora urgimos una respuesta a nuestra pregunta, ¿cómo es posible que actuemos moralmente?, encontramos que, si ésta existe, es o francamente evasiva o directamente insatisfactoria. Existe, en efecto, una valla que toda moral del deber, sea sistemática o crítica, no puede franquear en su búsqueda de una explicación para la acción moral, a saber: no hay un deber de actuar por deber. El regreso al infinito que inmediatamente se produciría si admitimos la afirmación contraria, cierra efectivamente toda salida en esta dirección. Por lo tanto, todas las maniobras que se intenten para responder a la cuestión planteada, estarán destinadas a rodear ese obstáculo con mayor o menor éxito. Yo voy a comentar sólo dos de ellas, sin duda las más prometedoras.

La primera es la intentada por el mismo Kant en la Metafísica de las costumbres, especialmente en la Doctrina de la virtud. ${ }^{\circ}$ Consiste fundamentalmente en un intento de analizar conceptualmente el 'deber' como si se tratara de 'querer'. En efecto, según Kant la noción misma de 'deber' contiene como nota distintiva la noción de 'coacción' (Nötigung). Pero ésta, a su vez, es inconcebible si no es como una forma de determinación a la acción, por contraposición a otra forma de

$5 F R, 3.2 ; 6.3$, etc., pp. 31 y 90 ss.

- $M S-T L$, IV, 508-511, cf. $K p V$, IV, pp. 142-144. Kant establece una distinción entre 'voluntad empirica' (Willkür) y 'voluntad' (Wille) únicamente con relación al 'fundamento de la determinación' (Bestimmungsgrund) que difiere en una (empírico) y en otra (racional), pero deja en claro que se trata de la misma facultad, cf. MS (Rechtslehre) IV, pp. 316-317. Para una exposición detallada de la teoría kantiana de la acción véase $K$. Cramer, "Hypothetische Imperative?", en: M. Riedel, ed, Rehabilitierung der praktischen Philosophie, Freiburg 1972, t. I, pp. 159-212, espec. pp. 167 ss. y O.N. Guariglia, "La renovación kantiana del derecho natural y la crítica de Hegel: una crítica a la crítica", Diálogos 45 (1985), pp. 7-49, espec. pp. 16 ss. 
determinación a la acción que es la inclinación. Ahora bien, la única facultad que puede determinar a la acción, cualquiera que ésta fuera, es la voluntad. En consecuencia, la acción por deber tiene lugar porque es querida por una voluntad positiva o natural. Así surge la famosa tesis kantiana de la voluntad inteligible, que en realidad es un puro querer racional. Hay muchos aspectos correctos detrás de esta teoría audaz y grandiosa, pero su punto de partida es inaceptable. En efecto, ciertamente podemos admitir que existe una relación conceptual inmediata entre la formulación de una voluntad, como por ejemplo 'quiero beber', y la realización de esa voluntad en la acción de tomar agua. Pero este tipo de relación conceptual es distinta de la que afecta al objeto del beber. En efecto, la proposición 'quiero $f$ ' es, en uso normal, redundante con la realización misma de $f$, de modo tal que si decimos: 'quiero beber' y comemos una galletita, lo que ipso facto queda falseado es la formulación lingüística, la cual no apuntó a la acción efectivamente querida. Si en cambio digo: 'debo ser sincero', pero de inmediato miento, no diremos que la incorrección está del lado de la fórmula lingüística, que no identifica de modo correcto lo que quiero, sino lo errado es, en este caso, la acción. La expresión de un deber, en consecuencia, no puede ser identificada según los criterios con la expresión de una voluntad.

La otra maniobra no enfrenta directamente la pregunta que hemos planteado, sino que da por supuesto que quien admite un juicio prescriptivo, cuyo contenido está determinado por la universalización de una máxima, debe admitir que su acción habrá de guiarse necesariamente por esa máxima, a menos que algo lo impida. Lo que, como consecuencia, se hace imprescindible explicar, no es cómo actuamos moralmente, sino, a la inversa, cómo es posible que conociendo qué debemos hacer, no lo realicemos. El problema de la acción ética se reduce, así, al enigma de la debilidad de la voluntad. Es Hare quien con mayor brillo utiliza este 
argumento, lanzado previamente contra su teoría ética, como una prueba definitiva en favor de ella. La línea de argumentación toma como hilo conductor el axioma lógico-práctico establecido por Kant: 'debo implica puedo'. Así como una imposibilidad física deja sin efecto o suspende para el caso singular la fuerza del 'debe', de la misma manera la debilidad de la voluntad opone al 'deber' una imposibilidad 'psicológica' que inhibe o suspende temporalmente la fuerza de prescripción." De esta manera, Hare nos propone una variante de la tesis socrática de que la moral se reduce al conocimiento de lo que es bueno y el vicio a la ignorancia. La variante consiste en restringir el campo ético a los problemas lógicos y deontológicos envueltos en los enunciados de las proposiciones prescriptivas que expresan un deber, desentendiéndose de las consecuencias pragmáticas de tales enunciados en tanto guías para la acción. Pues sin duda, tales consecuencias inevitablemente tendrán que vérselas con las características psicológicas de los seres humanos, ya que la acción involucra necesariamente a la persona en su conjunto, es decir como ente teórico, sensible y volitivo. Si todo lo relacionado con los afectos y las apetencias es empujado fuera del ámbito de la ética y entregado como una pieza de estudio a la psicología empírica, la ética renuncia por anticipado a todo contacto con la acción y se limita a establecer proposiciones normativas con sus correspondientes relaciones inferenciales. Como diría $M$. Weber y, tácitamente, refrenda Hare, jallá se entienda luego cada uno con el ángel o el demonio que lleva adentro!

2. Son estas inevitables vías de escape al escepticismo ético que afectan a la moral del deber en sus diveras formas, las que han provocado un comprensible malestar en diversos círculos filosóficos pertenecientes tanto a la tradición en lengua alemana como en lengua inglesa y española. En la

? FR, 5.8; pp. 80 ss. 
saludable reflexión retrospectiva que tal malestar ha desencadenado, aquellos defectos de la moral del deber mostraron astar estrechamente conectados con la cultura del individualismo liberal que emerge en Europa en las postrimerías del siglo XVII y extiende su influencia hasta hoy sobre el pensamiento filosófico-político y ético contemporáneo. Se trata, en efecto, de las consecuencias no queridas del 'solipsismo metodológico', como lo denomina acertadamente Apel, consecuencias que en su momento fueron denunciadas por los representantes de la teoría crítica desde los años treinta en adelante, y hoy por filósofos tales como $\mathrm{Ph}$. Foot ${ }^{8}$ y recientemente A. MacIntyre. ${ }^{\ominus}$

De esta manera ha tenido lugar un notable renacimiento de la antigua moral de la virtud, relegada durante siglos al polvoriento gabinete de los filólogos o al amurallado recinto de los tomistas. Creo, sin embargo, que hay una tercera fuente en el ámbito de la lengua española, en el que ha seguido abrevando la moral de la virtud y se ha mantenido viva en su exilio filosófico. Me refiero a su pervivencia como moral social que remonta sus orígenes al humanismo renacentista y perdura luego en la tradición literaria. Cito como única autoridad, una cuyo peso es imponderable: el Quijote: "... puesto que los cristianos, católicos y andantes caballeros más habemos de atender a la gloria de los siglos venideros, ... que a la vanidad de la fama que en este presente y acabable siglo se alcanza; ... así ¡Oh Sancho! que nuestras obras no han de salir del límite que nos tiene puesto la religión cristiana que profesamos. Hemos de matar en los gigantes a la soberbia; a la envidia, en la generosidad y buen pecho; a la ira, en el reposado continente y quietud del ánimo; a la gula y al sueño, en el poco comer que comemos y en el mucho velar que velamos; a la injuria y

8 Cf. "Morality as a System of Hypothetical Imperatives", en: Virtues and Vices, Oxford, 1977, pp. 167 ss.

9 a , passim. 
lascivia, en la lealtad que guardamos a la que hemos hecho señora de nuestros pensamientos...." Aunque fragmentario, aparece aquí el antiguo canon de las virtudes, asimilado ahora a una forma de moral católica adscrita a la vida intramundana. J.L. Abellán ha señaldo a Erasmo como la fuente de esta síntesis entre la moral pagana y moral religiosa seglar, cuya influencia en la ética española e hispanoamericana ha sido, a mi juicio, considerable. ${ }^{11}$

La moral de la virtud no ofrece las dificultades que hemos encontrado en la del deber con respecto a la traducción en acciones de las prescripciones teóricas emanadas de la razón. En efecto, como quiera que se entienda la virtud y como quiera que se escoja el canon de virtudes que la componen, existe una propiedad característica e indiscernible: su conexión intrínseca con una acción con sentido completo, esto es: no con una acción elemental o básica, sino con una práctica típica. Este aspecto ha sido con razón destacado por MacIntyre, ${ }^{12}$ quien precisa algunas de las características indispensables de tales prácticas, como constituir una forma coherente y compleja de actividad cooperativa humana social. mente establecida. Tales son, por ejemplo, deportes como el fútbol, el tenis, el ajedrez, etcétera. Es en efecto, mediante el ejercicio actual de algunas de esas prácticas que se demuestra la posesión de aquella propiedad en que consiste la virtud correspondiente. De ahí que Aristóteles haya expresamente distinguido la virtud, por una parte, y la capacidad o dynamis, por la otra. En un texto central para la comprensión de su concepción de la virtud, ${ }^{13}$ distingue entre la mera capacidad natural o genérica con que nacemos todos en tanto seres humanos y la virtud real (kyria), que es la efectiva-

10 M. de Cervantes Saavedra, El Ingenioso Hidalgo Don Quijote de la Mancha, ed. de C.S. de Cortazar e I. Lerner, Buenos Aires, 1969, t. II, p. 501. 11 Cf. Historia critica del pensamiento español, t. II: La Edad de Oro, Madrid, 1979, pp. 97 ss.

$12 A V$, pp. 175 ss.

$13 E N$, VI, $13,1144^{\text {b } 1 ~ s s . ~}$ 
mente poseída por aquellos que la han puesto de manifiesto en el ejercicio de la práctica correspondiente. Hay aquí al menos tres conceptos fuertemente entrelazados que es necesario separar. En primer lugar, el concepto aristotélico de acción como una unidad inescindible de deseo y espíritu práctico o teleológico, sin cualquiera de los cuales es imposible que ella tenga lugar. En efecto, como señala en $D e$ anima $I I I,{ }^{14}$ sin la participación de la razón fijada en un fin no hay posibilidad de que se produzca una acción identificable como acción del tipo A, B, etcétera, ya que lo que en ese caso tendríamos sería una serie de movimientos anárquicos que no se podrían captar bajo ninguna descripción. En segundo lugar, tenemos la tesis de que la virtud es una posesión (hexis) actual, como la visión o el conocimiento de la geometría o de una lengua, la cual presupone, por cierto, una disposición natural pero no se limita a ella, sino que requiere además haberse ejercitado y perfeccionado mediante la correspondiente actividad hasta alcanzar un grado aceptable, bueno u óptimo de realización de la misma manera. Por último, que todo ejercicio de una actividad virtuosa inevitablemente está unido a un concomitante ejercicio de una facultad intelectiva práctica, la phrónesis, que indica el fin correcto y establece la conexión con los medios adecuados.

A la pregunta, ¿cómo actuamos moralmente?, la moral de la virtud responde: de la misma manera que, en general, actuamos, uniendo el deseo de realizar una acción bajo esa descripción con la concepción de esa misma acción bajo esa misma descripción, tal que al concebirla de esa manera podamos establecer si los medios para llevarla a cabo están o no a nuestro alcance. Si la acción es, además, moralmente correcta, el bien intrínseco que presupone la acción para nosotros, será al mismo tiempo un bien en general que in-

$14 D A$, III, 11, 434 12-14. 
volucre al conjunto de los demás miembros de una cierta comunidad, familiar, amistosa, social y, por último, política.

Es, sin duda, una de las ventajas de la moral de la virtud el hecho de remitir de modo directo a los marcos institucionales de toda moral. Pues en esta concepción, actuar moralmente supone el haber actuado moralmente, y esto, a su vez, supone que toda acción moral como tal hunde sus raíces más allá del individuo que las realiza en una comunidad social, en la cual las reglas de la acción moral se transmiten de mayores a menores como cualquiera de las otras reglas que permiten la pervivencia de una determinada sociedad: el lenguaje, las artes y técnicas, etcétera.

Como la exégesis contemporánea de la moral aristotélica ha puesto de manifiesto, la virtud consiste en la alianza entre razonamiento práctico y deseo habitual, tal que quien la posee, "hace lo que debe, cuando se debe, por el fin debido y como se debe". ${ }^{15}$ En esta misma formulación aparece también con claridad el otro aspecto de la moral de la virtud: el hecho de concebir la acción como una entidad contingente y cambiante, que no se puede ni predecir completamente ni prefijar en sus diversos detalles. Es por ello que el error moral puede producirse por diversas razones, ya sea a causa de una deficiente comprensión de la norma general - la recta ratio-, ya sea porque no se saca la conclusión en el momento y en las circunstancias debidas $o$, ya sea, por último, porque en el acto de poner en marcha la conclusión, es decir de iniciar la acción, el deseo es desviado por la aparición de un objeto que ejerce sobre aquél una irrefrenable atracción contraria a la establecida. Como es sabido, tal es el caso del que padece de akrasia, es decir, de una forma de incontinencia que lo lleva a actuar en contra de aquello que sabe que está bien y es lo correcto. No me voy a detener en analizar las sutiles explicaciones que Aristóteles ha propuesto de este fenómeno moral, las cuales han dado lugar ${ }^{15} E N, 1106^{\text {b }} 21-24$. 
a un extensa literatura cuya sola reseña insumiría un tiempo desmesurado. Me voy a limitar a establecer un hecho que, a mi modo de ver, es completamente relevante con el problema que estamos tratando. Me refiero a la distinción entre el akratés y el akólastos, esto es: entre el incontinente y el depravado. Pues, a pesar de que ambos yerran moralmente, un abismo separa al uno del otro. En efecto, el incontinente comparte los mismos deseos correctos y el mismo conocimiento de lo que está bien que el hombre honesto, sólo que circunstancialmente falla o porque, llevado por su interés, confunde lo correcto con lo incorrecto, o porque no actúa con pleno sentido, como en el caso de un ebrio. El depravado, en cambio, no obra por error sino por cálculo. Tanto sus deseos como la concepción de las acciones que los cumplimentan, son el extremo opuesto del hombre virtuoso. Así como éste actúa moralmente porque desde niño ha sido ejercitado en la acción moral, que ahora de adulto identifica como la acción moral sin otra calificación, el depravado carece justamente de esta cultura moral que lo habilitaría luego para lograr la plena comprensión ética que da únicamente la acción por convicción. Aquí, por lo tanto, el paso de la disposición natural a la virtud real y efectiva está definitivamente cerrado. El depravado constituye, pues, la manifestación marginal, el excluido del mundo moral. Por definición, su acción es inmoral.

Desde sus comienzos y por su misma naturaleza, la moral de la virtud tiende a convertirse en un código de conducta para los miembros de un grupo social más o menos extenso, pero normalmente exclusivo y excluyente. En la época de su cristalización definitiva en el siglo IV a.C. constituye la expresión de las normas de conducta de esa peculiar aristocracia ciudadana de guerreros, que era la polis griega y continuará siendo la base de la organización social y política del mundo antiguo hasta la época imperial. No quiero afirmar que este solo rasgo la condena irremediablemente. 
A mi juicio, MacIntyre tiene razón en subrayar que, a pesar de sus limitaciones y conflictos intrínsecos, ésta era la única forma de moral coherente y compacta que involucraba todos los órdenes de la vida sin establecer la fatal diferencia entre lo privado y lo público que hoy impera. Por otra parte, como ha mostrado con acierto M. Weber, todo tipo de acción racional-valorativa, de Wertrationalität, así sea la del personaje más humilde, como el monje mendicante budista, engendra irremisiblemente una élite de los elegidos, que los separa tajantemente del vulgo. Desde este punto de vista, la moral de la virtud tiene el mérito de ser mucho más próxima al funcionamiento moral fáctico de la sociedad. De ahí su tendencia a convertirse en teoría social, política o filosofía de la historia, como ocurre con esa moral de la virtud sin virtudes que constituye la eticidad de Hegel. ${ }^{16}$

Por todo ello es que dudo mucho que una moral de la virtud así concebida, que tiende a fraguar en códigos éticos antagónicos sin posibilidad de mediación entre sí, constituya la moral apropiada y requerida para un mundo como el actual, constituido por sociedades nacionales que no son, en última instancia, más que un inosaico de culturas distintas superpuestas. Si en el caso de la moral del deber, la formulación de una propuesta normativa teórica en la que ésta se agota abre la vía de escape al escepticismo ético privado, aquí, en el caso de la moral de la virtud, la inevitable fragmentación en códigos de conducta restringidos y contrapuestos entre sí abre la vía de escape al relativismo cultural y con él al relativismo moral. A su vez, la contraposición entre códigos alternativos de conducta sin mediación teórica posible entre sí es, potencialmente, la fuente de los conflictos más catastróficos que han tenido lugar en nuestro siglo. No es posible ocultar que sobre la base de la moral aristotélica de la virtud, Carl Schmitt, el ideólogo del fas-

16 Cf. O.N. Guariglia, "La cancelación hegeliana de la ética: origen y consecuencias" Revista Latinoamericana de Filosofia, 10 (1984), pp. 231-253. 
cismo alemán, desarrolló su teoría de lo político como la confrontación interna entre amigo y enemigo.

3. Como anticipé al comienzo, el resultado de este examen es una aporía. Ninguna de ambas morales que hemos considerado logra formular una respuesta completamente satisfactoria al problema de la acción moral. La intención de mi examen no es, en modo alguno, el contentarse con una conclusión pesimista. Todo lo contrario, es mi convicción que el hecho de formular con claridad los polos opuestos de la aporía es ya un primer paso en el camino hacia su solución. En cada una de ellas, en efecto, encontramos un componente indispensable de toda moral posible: en la moral del deber, el principio universalizante, heredado de los estoicos, que hace de todo ser humano, por ser tal, un ser capaz de recibir en sí el germen de la razón, el logos que lo transforme y haga efectiva su dignidad como persona; en la moral de la virtud, el principio de la acción que involucra a todo ser humano como un organismo biológico real, con sus deseos y aspiraciones pero también con la comprensión intelectual de sus actos, realizados por sí mismos por ser en sí valiosos, y no por mera imposición. De esta manera, tanto el deber requiere alguna forma de virtud que no sea mera obediencia para ser cumplimentado, como la virtud necesita algún criterio formal que sobrevenga a los actos virtuosos para poder ser universalmente juzgada. En otras palabras, si por una moral entendemos también una guía efectiva de conducta para la vida práctica, tal como ésta se nos presenta en las circunstancias fácticas en las que es efectivamente vivida, la moral que necesitamos debería complementar una moral del deber con una moral de la virtud. Si tal utopía fuera posible, cosa que por ahora ignoro, la aporía estaría resuelta. 


\section{REFERENCIAS BIBLIOGRAFICAS}

Aristóteles, De Anima, ed. con comentario de Sir David Ross, Oxford 1961. = DA. Ethica Nicomachea, ed. I. Bywater, Oxford ('1894) $1962=E N$.

Hare, R. M. Freedom and Reason, Oxford (11963) $1978=F R$.

Kant, I. Kritik der praktischen Vernunft, en: Werke, ed. por W. Weischedel en 6 tomos, Darmstadt, $1966=K p V$.

Metaphysik der Sitten, 2. Teil: Metaphysische Anfangsgründe der Tugendlehre (1797), en: Werke, ed. W. Weischedel, Darmstadt, 1966, t. IV $=M S-T L$.

MacIntyre, A. After Virtue, Notre Dame, 1981. $=A V$.

Nelson, L. Kritik der praktischen Vernunft, Gesammelte Schriften, t. IV, Hamburg $\left({ }^{1} 1917\right){ }^{2} 1972=K p V$.

\section{S U M M A R Y}

This paper is a discussion of the problem of translating theoretically well founded normative propositions into behaviourary maxims effectively applicable for moral agents. To this end I consider, in the first place, the solution proposed by the theorists of moral duty in its two forms: systematic morality and critical morality. First, the Kantian theory of inteligible will is examined and shown to be unsatisfactory. Secondly, I consider Hare's proposal which presents itself as a variant on the problem of the weakness of the will; this solution turns out to be unsatisfactory as well. Then I consider the solution afforded by the morality of virtue from Aristotle to MacIntyre, in particular its application to the distinction between the akratés and the akólastos. It is shown in what manner this solution can open the way to cultural relativism, and from there to morality. I conclude by pointing out that the problem is at present an insoluble one whose terms I have tried to clarify. 